\title{
MAPEAMENTO DE SUSCETIBILIDADE E DE PERIGO À EROSÃO E INVENTÁRIO DE CICATRIZES EROSIVAS NA ZONA DA MATA SETENTRIONAL PERNAMBUCANA
}

\author{
SUSCEPTIBILITY AND HAZARD EROSION MAPPING AND EROSIVE SCARS INVENTORY IN PERNAMBUCO NORTHERN \\ FOREST AREA
}

\section{RESUMO}

A previsão de processos erosivos tem passado por um aprimoramento a partir da utilização de Sistemas de Informações Geográficas (SIG), destacando-se as análises multicritério, que possibilitam integrar diversos fatores condicionantes (ex: clima, relevo, solo, litologia, uso da terra entre outros) destes processos. O objetivo deste trabalho é identificar as áreas de maior perigo à erosão do município de Aliança, Zona da Mata Setentrional Pernambucana, onde é comum a ocorrência de feições erosivas, a partir da associação entre a carta de suscetibilidade e a carta de uso da terra, validando-a a partir da sobreposição com um inventário de cicatrizes erosivas. A carta de suscetibilidade foi obtida por meio de uma análise sistêmica dos fatores condicionantes naturais e a carta de uso e ocupação da terra, pela fotointerpretação de imagens de satélite, todas em escala municipal. Os resultados indicaram que embora haja solos altamente erodíveis no município, a capacidade da chuva erodi-los é relativamente fraca, revelando, que outros fatores condicionantes (ex. cobertura pedológica) e os fatores antrópicos possuem um papel relevante na deflagração dos processos erosivos.

Palavras-chave: Erosão. Análise Multicritério. Lógica Fuzzy. Suscetibilidade. Perigo.

\section{ABSTRACT}

The prediction of erosion processes has been an improvement from the use of Geographic Information Systems (GIS), highlighting the multi-criteria analysis, that make it possible to integrate various conditions (eg, climate, slope, soil, lithology, land use, among others) of these processes. The aim of this study is to identify the areas of greatest danger to erosion of the city of Aliança, Northern Zona da Mata, Pernambuco, where is the common occurrence of erosive features, from the association between the letter of susceptibility and the letter of land, by validating the from the overlap with an inventory of erosive scars. The letter of susceptibility was achieved through a systemic analysis of the natural conditions and the use and occupation of the Earth by photointerpretation of satellite imagery, all municipal scale. The results indicated that although there are highly erodible soils in the municipality, the ability of rain erode them is relatively low, revealing other conditions (e.g. pedological cover) and man-made factors have played an important role in the generation of erosive processes.

Keywords: Erosion. Multicriteria Analysis. Fuzzy Logic. Susceptibility. Hazard.
D Joaquim Pedro de Santana Xavier $^{\text {a }}$

(D) Fabrizio de Luiz Rosito Listo ${ }^{a}$

${ }^{a}$ Universidade Federal de Pernambuco (UFPE), Recife, PE, Brasil

DOI: $10.12957 /$ geouerj.2020.34265

Correpondência: fabriziolisto@gmail.com

Recebido em: 21 maio 2018

Revisado em: 6 jun. 2019

Aceito em: 3 ago. 2020 


\section{INTRODUÇÃO}

Estudos de processos erosivos associados ao planejamento sócio-ambiental envolvem uma série de conceitos, muitas vezes utilizados de forma indiscriminada, tais como suscetibilidade, vulnerabilidade, perigo, risco, entre outros. Inúmeros trabalhos já utilizaram essas terminologias, muitas vezes com semânticas distintas, mas com técnicas metodológicas semelhantes que, por vezes, chegam a resultados parecidos (MARANDOLA JUNIOR e HOGAN, 2004, p. 96; CASTRO et al., 2005, p. 12).

Marandola Junior e Hogan (2004, p. 101) e Augusto Filho (2001, p. 35), por exemplo, identificaram que existe uma confusão conceitual, muitas vezes, derivadas de traduções dos termos Hazard, ora utilizado como risco, ora como perigo. Castro et al. (2005, p. 13) apontam que esse mesmo problema semântico pode ocorrer com os termos em inglês risk e danger e com os termos em francês risques e danger. O conceito de risco, notadamente, envolve a probabilidade de um evento (ex. um processo erosivo) causar consequências negativas com danos potenciais (perdas materiais e de vidas), abordado por Varnes et al. (1984, p. 19), UNDP (2004, p. 24), Castro et al. (2005, p. 13), Carvalho et al. (2007, p. 24), entre outros.

Muitas vezes o conceito de risco (R) é expresso em equações como $R=P+V$ (REBELO, 2001, p. 20; UNDP, 2003, p. 17; BRAGA et al., 2006, p. 84); R= PxV (REBELO, 2001, p. 20), entre outros. Seja qual for a equação empregada, observa-se que é explícita a relação entre a vulnerabilidade (V), definida como o grau de perda, fragilidade e resiliência de elementos antrópicos passíveis de serem afetados por um processo, o qual discorre Varnes et al. (1984, p. 31) e Braga et al. (2006, , p. 87) e perigo (P), definido como a probabilidade ou a ameaça potencial de um processo para causar consequência desagradável a pessoas ou a bens (BRASIL, 2007, p. 25).

Neste trabalho, o termo suscetibilidade é empregado na potencialidade de ocorrência de um processo, considerando apenas as variáveis naturais do terreno, tal como as características geológicas, pedológicas, geomorfológicas, climáticas, entre outras (BRASIL, 2007, p. 25). Ao analisar a gênese do processo erosivo pela integração dos fatores de suscetibilidade juntamente com o fator uso da terra (antrópico), optou-se pelo emprego do termo perigo. Esta mesma opção foi observada em trabalhos pré-existentes na literatura, tais como Castro et al. (2005, p. 16) entre outros.

O controle da erosão tem passado por um aprimoramento a partir da utilização de Sistemas de Informações Geográficas (SIG). Dentre diversas metodologias destacam-se as análises multicritérios, que possibilitam integrar diversos fatores condicionantes dos processos erosivos, naturais e antrópicos (VALLADARES et al., 2012, p. 1378). Meirelles et al. (2007, p. 113) constataram que os métodos de inferência geográfica realizados em SIG baseados em uma Lógica Fuzzy obtiveram os melhores resultados na realização de diversos estudos ambientais. Assim, a avaliação multicritério baseada nessa lógica, oferece uma vasta 
disponibilidade de técnicas e de procedimentos, que permitem revelar as preferências de decisões para o planejamento urbano.

A técnica multicritério foi bastante teorizada por Ross (1994) em estudos de fragilidade ambiental; por Crepani et al. (2001) para o zoneamento e o planejamento ambiental, entre outros. Os referidos autores fundamentaram-se no conceito de Ecodinâmica, que influenciou os estudos de Menezes et al. (2007) e Silva e Barbosa Neto (2016), em ambientes semiáridos e úmidos, respectivamente, no estado de Pernambuco. Podem-se citar, ainda, demais trabalhos no cenário nacional como: Valladares et al., (2012); Fantinel e Benedetti (2016) e Messias e Ferreira (2017).

Somente no Estado de Pernambuco foram oficialmente registradas, entre 1991 e 2012, 32 ocorrências de erosão, sobretudo lineares (ravinas e voçorocas) e costeiras em áreas como a Região Metropolitana do Recife, Zona da Mata e Agreste Pernambucano (UFSC-CEPED, 2013), muitas vezes influenciadas por usos não conservacionistas, comprometendo, por exemplo, a qualidade de áreas agrícolas. Nesse contexto, destaca-se a Zona da Mata Pernambucana setentrional, tradicional área de cultivos agrícolas, principalmente pela plantação de cana-de-açúcar desde o período colonial.

Inserido nesta região, o município de Aliança, ainda mantém esta tradição econômica, porém com o declínio do ciclo do açúcar, as monoculturas de cana foram reduzidas, sobretudo em função da falência de engenhos e de usinas sucroalcooleiras da área. Dessa forma, grandes áreas de cultivo de cana foram substituídas por pastos, por vegetação rasteira de gramíneas e por áreas com solo exposto, degradadas e mais suscetíveis a processos erosivos, em função da potencialização do escoamento superficial. Assim, o objetivo deste trabalho é identificar as áreas de maior perigo à erosão do município, a partir da associação entre a carta de suscetibilidade e a carta de uso da terra, validando-a a partir da sobreposição com um inventário de cicatrizes erosivas.

\section{ÁREA DE ESTUDO}

O município de Aliança localiza-se na mesorregião da Zona da Mata Setentrional Pernambucana, distando 72 km da capital Recife com área administrativa de 272 km² (Figura 1). Situa-se, majoritariamente, nos níveis cristalinos antecedentes ao Planalto da Borborema, com altitudes variando de $0 \mathrm{~m}$ a $334 \mathrm{~m}$. Encontra-se, portanto, em uma área de transição entre os Tabuleiros Costeiros Sedimentares a leste (Planalto Sedimentar) e à Borborema a oeste apresentando em seu relevo, morros e colinas bastante dissecadas pela drenagem com formas pluriconvexas, típicas da Zona da Mata, na qual é comum a presença de cicatrizes erosivas (CPRM, 2005). 
Figura 1. Localização do município de Aliança-PE. Fonte: autores.

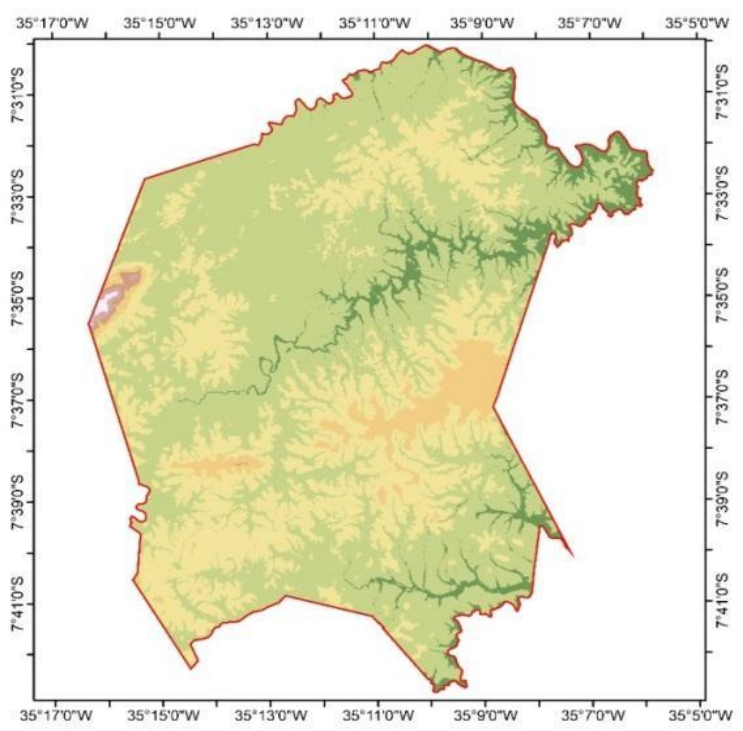

MAPA HIPSOMÉTRICO

ALIANÇA (PE)
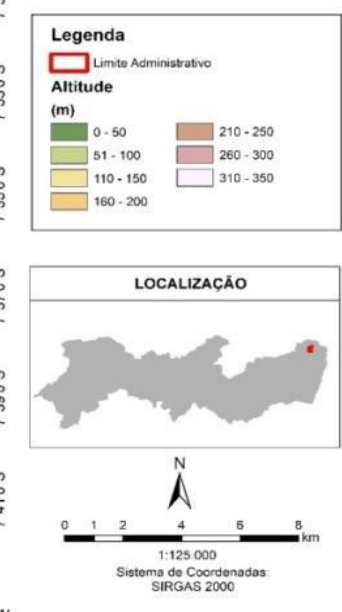

É geologicamente dividido em grandes unidades, tais como o Complexo Salgadinho (rochas metamórficas paleoproterozóicas, ex. ortognaisses tonalíticos e graníticos); Complexo Vertentes (de caráter metavulcanossedimentar mesoproterozóico composto por rochas metavulcânicas máficas e intermediárias, como quartzitos); Granitóides indiscrinados neoproterozóicos (rochas plutônicas e metavulcânicas, ex. granitos) e pela Formação Barreiras (formação sedimentar cenozóica composta, principalmente, de arenitos) segundo o CPRM (2005, p. 14). Essa variabilidade litológica pode favorecer ou reduzir a possibilidade e a gênese de processos erosivos, uma vez que há tanto litotipos mais resistentes ao intemperismo quanto aqueles que favorecem a morfogênese.

Apresenta clima tropical quente e úmido, com chuvas de outono-inverno (As' conforme Köppen) com totais pluviométricos anuais de $1190 \mathrm{~mm}$. Dentre os sistemas atmosféricos atuantes, destaca-se a influência da ZCIT (Zona de Convergência Intertropical) e dos distúrbios ondulatórios de leste (DOL), responsáveis pelo aumento da precipitação na costa do Nordeste brasileiro, além dos Vórtices Ciclônicos de Altos Níveis (VCANs), que penetram na região e se formam no Oceano Atlântico. De acordo com Vasconcelos Sobrinho (1949), tais características climáticas permitiram uma vegetação primária de mata seca (subcaducifólia), ora substituída por cana-de-açúcar ainda no período colonial.

Sobre as superfícies suaves e onduladas verificam-se solos do tipo Planossolos e Argissolos, altamente suscetíveis a processos erosivos devido ao incremento do teor de argila no horizonte $\mathrm{B}$, favorecendo o escoamento superficial; solos menos desenvolvidos, como Litólicos; e nos fundos de vales, os Gleissolos (CPRM, 2005, p. 25). A presença destes diferentes solos caracteriza a grande variabilidade de paisagens que, ora favorecem a pedogênese, ora a morfogênese. Por fim, a região tem uma rede de drenagem bastante desenvolvida, fazendo parte da bacia do Rio Goiana, sendo o município drenado por um dos principais rios da bacia, o Rio Siriji. 


\section{MATERIAIS E MÉTODOS}

Mapeamentos temáticos (fatores condicionantes naturais) e Carta de Suscetibilidade

Conforme os objetivos do trabalho, os mapeamentos foram realizados/adaptados para a escala municipal (1:25.000). Os mapas temáticos (pluviometria, declividade, formas da encosta, geologia e tipos de solo) foram utilizados de forma integrada para a análise da suscetibilidade. Assim, a carta de suscetibilidade a erosão, realizada a partir da análise multicritério, utilizou a Logica Fuzzy com o operador Fuzzy ponderado, hierarquizando os fatores condicionantes da suscetibilidade de acordo com a importância para a gênese erosiva.

Primeiramente foi atribuído um valor em uma escala de 1-3 em cada classe temática para cada fator condicionante (ex. classe de declividade $>45^{\circ}$, peso 3, importância forte). Foram utilizados pesos consagrados na literatura (ex. CREPANI et al., 2001), adaptados e validados em campo de acordo com a realidade de Aliança. Posteriormente, cada mapa temático recebeu um peso que variou em uma escala de $0 \%-100 \%$ (0-1) utilizando o operador Fuzzy ponderado. Assim, nesta etapa, os pesos foram atribuídos à cada mapa, visando indicar a influência de cada fator condicionante na potencialização erosiva (Equação 1).

$$
S e=(I p * 0,25)+(S * 0,25)+(D * 0,2)+(C * 0,15)+(L * 0,15) \quad \text { (Equação } 1)
$$

Onde: Se=Suscetibilidade a erosão; Ip=fator intensidade pluviométrica; $S=$ fator solo; $D=$ fator declividade do relevo; $C=$ fator forma do relevo e $L=$ fator litologia.

O fator intensidade pluviométrica, que fornece energia ao sistema, e o fator solo, que recebe a energia do sistema, receberam os maiores pesos (25\%), devido a sua relevância para a gênese do processo erosivo. Nos demais fatores, a declividade recebeu um peso de $20 \%$ e os fatores formas da encosta e litologia receberam $15 \%$ devido a análise realizada em campo quanto às suas influências na deflagração dos processos erosivos do município.

Figura 2. Postos pluviométricos utilizados. Fonte: Elaborado pelos autores a partir de dados fornecidos pela APAC. 


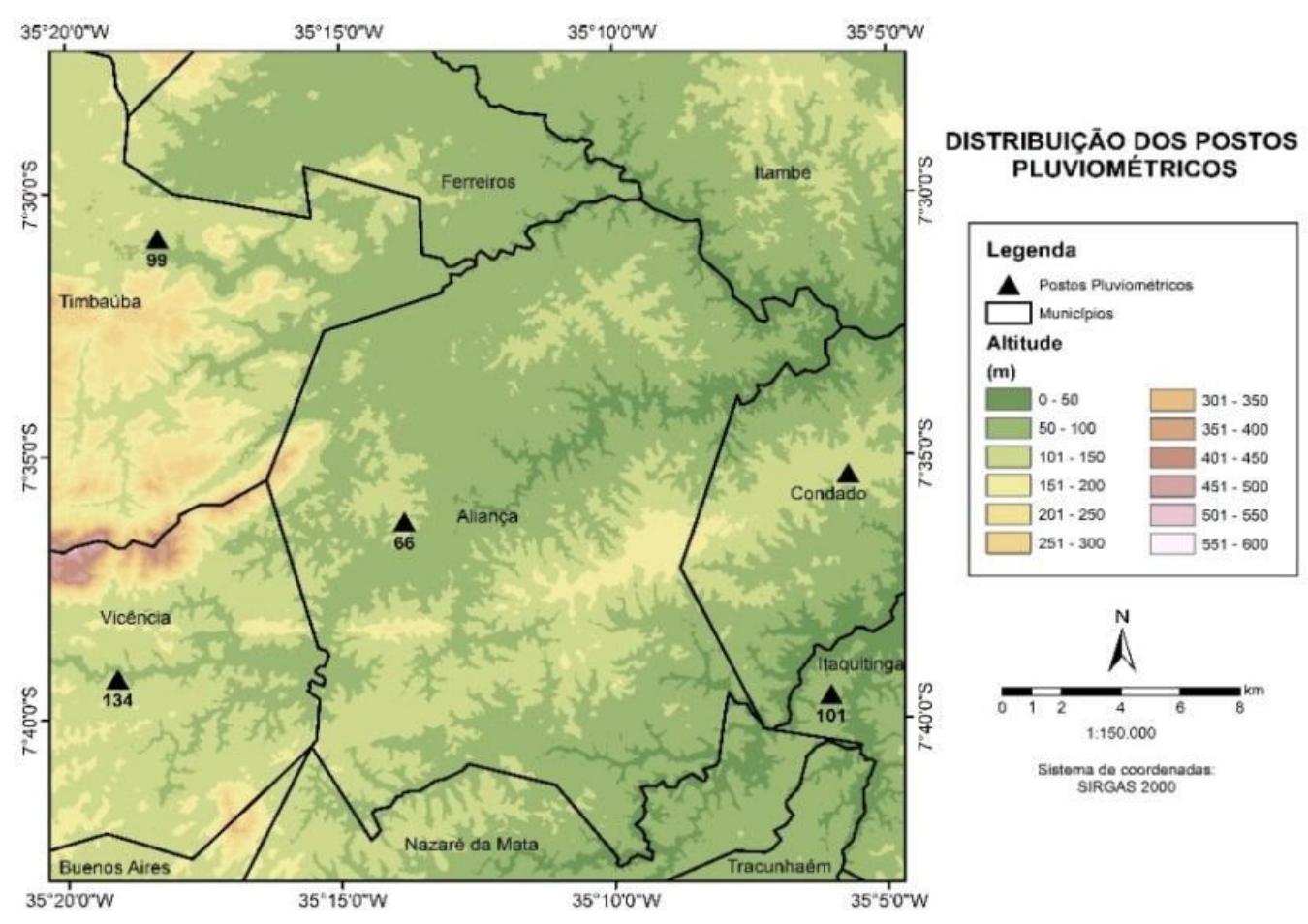

Os parâmetros pluviométricos foram obtidos por meio de banco de dados da Agência Pernambucana de Águas e Clima (APAC). Foram selecionados 5 postos pluviométricos do município de Aliança e de municípios vizinhos dentro de uma série histórica com um mínimo de 10 anos para cada posto (Tabela 1 e Figura 2). Foi realizado o procedimento geoestatístico em ambiente SIG denominado Interpolação pela Ponderação do Inverso da Distância (IDW), que se baseia na suposição de que o valor em um ponto sem amostragem pode ser aproximado com uma média ponderada de pontos com valores conhecidos.

Tabela 1. Dados pluviométricos e seus respetivos pesos atribuídos ao critério intensidade pluviométrica. Foi utilizada uma série histórica de 10 anos (ao invés de 30 anos conforme prevê a normal climatológica) em razão da ausência de dados disponíveis para a região. Fonte: APAC.

\begin{tabular}{|c|c|c|c|c|c|}
\hline Código do Posto & 66 & 99 & 131 & 134 & 101 \\
\hline Município & Aliança & Timbaúba & Condado & Vicência & Itaquitinga \\
\hline Coordenadas & $\begin{array}{l}07^{\circ} 36^{\prime} 15^{\prime \prime} \mathrm{S} \\
35^{\circ} 13^{\prime} 50^{\prime \prime} \mathrm{W}\end{array}$ & $\begin{array}{l}07^{\circ} 30^{\prime} 51^{\prime \prime} \mathrm{S} \\
35^{\circ} 18^{\prime} 20^{\prime \prime} \mathrm{W}\end{array}$ & $\begin{array}{l}07^{\circ} 35^{\prime} 22^{\prime \prime} \mathrm{S} \\
35^{\circ} 05^{\prime} 43^{\prime \prime} \mathrm{W}\end{array}$ & $\begin{array}{l}07^{\circ} 39^{\prime} 13^{\prime \prime} \mathrm{S} \\
35^{\circ} 19^{\prime} 05^{\prime \prime} \mathrm{W}\end{array}$ & $\begin{array}{l}07^{\circ} 39^{\prime} 34^{\prime \prime} \mathrm{S} \\
35^{\circ} 06^{\prime} 02^{\prime \prime} \mathrm{W}\end{array}$ \\
\hline Série histórica & $\begin{array}{l}2001-2007 \\
2014-2016\end{array}$ & 2007-2016 & $\begin{array}{l}\text { 1996-2001; } \\
\text { 2013-2016 }\end{array}$ & $\begin{array}{l}\text { 2001-2006; } \\
\text { 2013-2016 }\end{array}$ & $\begin{array}{l}\text { 1995-2000; } \\
\text { 2013-2016 }\end{array}$ \\
\hline Pluviometria média anual (mm) & 1050,66 & 523,62 & 1156,06 & 910,7 & 1063,14 \\
\hline Intensidade pluviométrica (mm/mês) & 210,132 & 104,724 & 229,212 & 182,14 & 212,628 \\
\hline $\begin{array}{l}\text { Suscetibilidade (1-3) e grau de importância } \\
\text { (CREPANI et al., 2001) }\end{array}$ & $\begin{array}{l}\text { 1,7 (Média- } \\
\text { Fraca) }\end{array}$ & 1,3 (Fraca) & 1,8 (Média) & $\begin{array}{l}\text { 1,6 (Média- } \\
\text { Fraca) }\end{array}$ & $\begin{array}{l}\text { 1,7 (Média- } \\
\text { Fraca) }\end{array}$ \\
\hline
\end{tabular}

Os parâmetros pedológicos foram obtidos pelo mapeamento de solos da PROMATA (Programa de Apoio ao Desenvolvimento Sustentável da Zona da Mata de Pernambuco), realizado pelo Instituto Agrônomo de Pernambuco (IPA) e pela Empresa Brasileira de Pesquisa Agropecuária (EMBRAPA) (Tabela 2). Os mapas de declividade e de formas da encosta foram elaborados a partir de um Modelo Digital do Terreno (MDT) de alta 
resolução $\left(1 \mathrm{~m}^{2}\right)$ por meio da digitalização de seis cartas topográficas em escala 1:25.000 fornecidas pelo Exército Brasileiro, cujos pesos são demonstrados na Tabela 3 e na Tabela 4. A carta de Litologia foi gerada a partir da compilação de dados fornecidos pela Companhia de Pesquisa de Recursos Minerais (CPRM, 2005, p. 97) (Tabela 5).

Tabela 2. Atribuição dos pesos para as classes de solos. Fonte: Adaptado de Crepani et al. (2001).

\begin{tabular}{ccc}
\hline & SOLOS & \\
\hline CLASSES & PESO (1-3) & IMPORTÂNCIA \\
Argissolo Vermelho & 3 & Forte \\
Argissolo Vermelho-Amarelo & 3 & Forte \\
Neossolo Litólico & 3 & Forte \\
Planossolo Háplico & 2 & Média \\
Gleissolo Háplico & 3 & Forte \\
\hline
\end{tabular}

Tabela 3. Atribuição dos pesos para as classes de declividade. Fonte: Adaptado de Crepani et al. (2001).

\begin{tabular}{ccc}
\hline & DECLIVIDADE & \\
\hline CLASSES & PESO (1-3) & IMPORTÂNCIA \\
\hline$<2 \%$ & 1 & Fraca \\
$2 \%-6 \%$ & 1,5 & Fraca-Média \\
$6 \%-20 \%$ & 2 & Média \\
$20 \%-50 \%$ & 2,5 & Média-Forte \\
$>50 \%$ & 3 & Forte \\
\hline
\end{tabular}

Tabela 4. Atribuição dos pesos para as classes de curvatura (formas da encosta). Fonte: Autores.

\begin{tabular}{ccc}
\hline & CURVATURA & \\
\hline CLASSES & PESO (1-3) & IMPORTÂNCIA \\
\hline Côncavo & 3 & Forte \\
Retilíneo & 2 & Média \\
Convexo & 1 & Fraca \\
\hline
\end{tabular}

Tabela 5. Atribuição dos pesos para as classes de litologia. Fonte: Adaptado de Crepani et al. (2001).

\begin{tabular}{|c|c|c|c|}
\hline \multicolumn{4}{|c|}{ LITOLOGIA } \\
\hline CLASSES & LITOTIPOS & $\begin{array}{l}\text { PESO } \\
(1-3)\end{array}$ & IMPORTÂNCIA \\
\hline Complexo Salgadinho & Ortognaisse tonalítico e granítico & 3 & Média \\
\hline Grupo Barreiras & Arenito, conglomerado e siltito & 3 & Forte \\
\hline Complexo Vertentes & $\begin{array}{l}\text { Quartzito, metapelitos e rochas } \\
\text { metavulcânicas }\end{array}$ & 2 & Média \\
\hline $\begin{array}{c}\text { Granitoides } \\
\text { indiscriminados }\end{array}$ & Granito, granodiorito, monzogranito. & 1 & Fraca \\
\hline
\end{tabular}

\section{Carta de Uso e Cobertura da Terra e Carta de Perigo a erosão}

A carta de uso e cobertura da terra objetiva avaliar os impactos antrópicos sobre a paisagem, potencializando ou protegendo a paisagem de processos erosivos. Esta foi elaborada por meio da 
interpretação de imagens de satélite obtidas no Google Earth Pro e do satélite RapidEye em escala 1:25.000, cuja legenda foi baseada em Almeida e Freitas (1996, p. 197) e Valladares et al. (2012, p. 1380) (Tabela 6).

Tabela 6. Atribuição dos pesos para as classes de litologia. Fonte: Adaptado de Crepani et al. (2001).

\begin{tabular}{ccc}
\hline & USO DA TERRA & \\
\hline CLASSES & PESO (1-3) & IMPORTÂNCIA \\
\hline Açude & 1 & Fraca \\
Mata & 1 & Fraca \\
Área Edificada & 1,5 & Fraca-Média \\
Vegetação Herbácea & 1,8 & Média \\
Áreas agrícolas & 2 & Média \\
Pastagem & 2,3 & Média-Forte \\
Cana-de-açúcar & 2,5 & Média-Forte \\
Solo Exposto & 3 & Forte \\
\hline
\end{tabular}

A carta de Perigo a erosão, associação entre a carta de suscetibilidade e a de uso e ocupação da terra, foi realizada em ambiente SIG por meio da Equação 2. Os valores dos pesos seguiram a proposta de Crepani et al. (2001, p. 74), dos quais quanto mais importante for determinada classe na instabilidade do sistema, maior será seu valor atingindo (até o valor 3).

$$
P=\frac{S e+U O t}{2}
$$

Onde: $P=$ Perigo a erosão; $S e=$ Suscetibilidade a erosão e UOt= Uso e ocupação da terra. $A$ soma dos valores das cartas de suscetibilidade a erosão e a de uso e ocupação da terra foram divididas por dois (2), em razão da aplicação do operador fuzzy média, cujos va lores são manipulados em função de uma média matemática simples.

Inventário das cicatrizes de erosão e validação das cartas

O inventário foi realizado a partir da interpretação de imagens de satélite disponíveis no software Google Earth Pro. Estas foram identificadas de acordo com as características/critérios das formas resultantes da erosão (feições em formato de "V" nas encostas, exposição do solo, aspecto alongado, etc.). As cicatrizes foram sobrepostas à Carta de Perigo visando correlacionar o grau de perigo que coincidiu com cada feição erosiva mapeada.

Para a validação final da carta de perigo, foi realizado o cálculo do índice Concentração de Erosão (CE), isto é, a razão entre o número de células de cada classe afetada (ex. perigo forte) pelas cicatrizes erosivas e o total de células do município. Em todos os mapas temáticos foi calculado também o índice Frequência de Distribuição (FD), que indica em porcentagem o valor de cada classe nos mapeamentos. Além disso, foram analisadas 5 cicatrizes erosivas de forma mais detalhada a partir de visitas em campo. 


\section{RESULTADOS E DISCUSSÕES}

De acordo com os fatores condicionantes analisados neste trabalho, a intensidade pluviométrica representa a capacidade de erodir o solo (quantidade de chuva em $\mathrm{mm}$, o tempo e a frequência em que ocorre a precipitação). A relação intensidade e duração da chuva, muitas vezes, alteram o sistema geomorfológico, desagregando partículas de solo. A pedologia (tipos de solo) é o fator que, desprovido de cobertura vegetal, recebe toda a energia cinética das gotas de chuva e, a depender da sua resistência (erodibilidade do solo), resultará no desprendimento das partículas e, consequentemente, na erosão.

A geologia é um fator que indica informações relativas ao grau de coesão das rochas que a compõem, ou seja, a intensidade da ligação entre os minerais ou das partículas que as constituem. A declividade pode alterar a velocidade do escoamento superficial na medida em que, quanto maior a declividade, maior a velocidade do runoff. As formas da encosta (côncava, retilínea e convexa) são características que influenciam na difusão ou na concentração de fluxos hídricos. As atividades antrópicas provocam alterações na paisagem (desmatamento, agricultura, obras urbanas, viárias, etc.) que, modificam a concentração das águas do escoamento superficial.

\section{Fatores Condicionantes Naturais e Carta de Suscetibilidade a Erosão}

A pluviometria de Aliança (Figura 3) variou entre 812 mm e 1115 mm em média dentro da série histórica utilizada. Possui a tendência de diminuir na medida em que se afasta do litoral, fazendo com que as áreas mais a oeste e a noroeste apresentem os menores valores, ao passo que as áreas mais a leste e central apresentem os maiores totais pluviométricos. O fator intensidade da chuva apresentou, em sua maior parte, valores de grau de suscetibilidade média-fraca, tais como 1,5 (0,11\%); $1,6(30,7 \%)$ e 1,7 (67,9\%), ou seja, 98,7\% deste fator possui suscetibilidade média-fraca a erosão e apenas 1,3\% médio (Figura 4).

No fator solo (Figura 3) é predominante a classe Argissolo, com FD de 63\% (Figura 4), distribuída nas áreas centrais e a oeste. Os Argissolos, os Neossolos (a oeste com FD de 23\%) e os Gleissolos (áreas com influência da drenagem com FD de 17\%) possuem uma suscetibilidade a erosão forte (Figura 4). Dessa forma, 98\% da FD dos solos de Aliança possuem um grau de suscetibilidade a erosão forte (Figura 4). Os Planossolos (suscetibilidade média) ocorrem em apenas 2\%, restringindo-se a sudoeste (Figura 3 e Figura 4). É importante destacar que a intensidade pluviométrica apresentou, predominantemente, classes de suscetibilidade médiofraca, enquanto o fator solo, forte. O município apresenta solos com alta erodibilidade, porém a chuva possui uma capacidade menor para a gênese erosiva e que, ao considerar apenas os fatores naturais, demonstra um equilíbrio ambiental, dificultando o aparecimento de erosão. 
Figura 3. Fatores condicionantes naturais a erosão: a) Pluviometria; b) Declividade; c) Formas da encosta; d) Solos; e) Litologia. Fonte: autores.
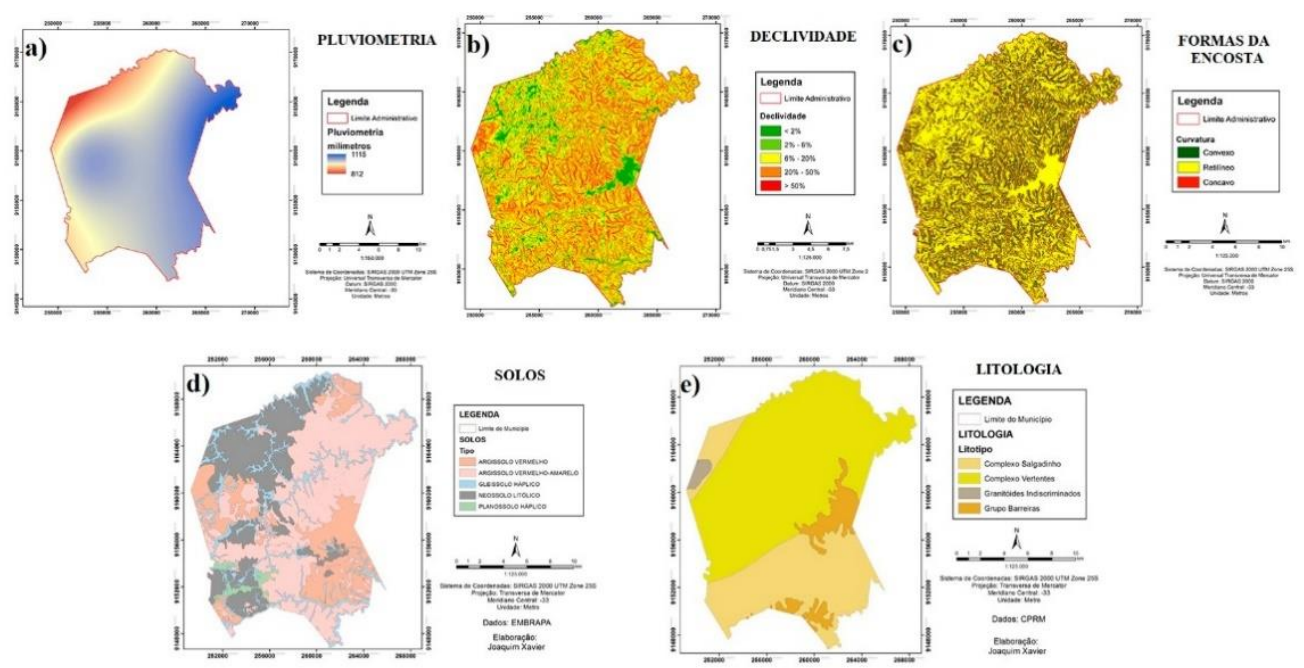

Figura 4. Frequência de Distribuição (FD) dos fatores Intensidade Pluviométrica (a); Declividade (b); Formas da encosta (c); Solos (d); Grupos litólicos (e). Fonte: autores.

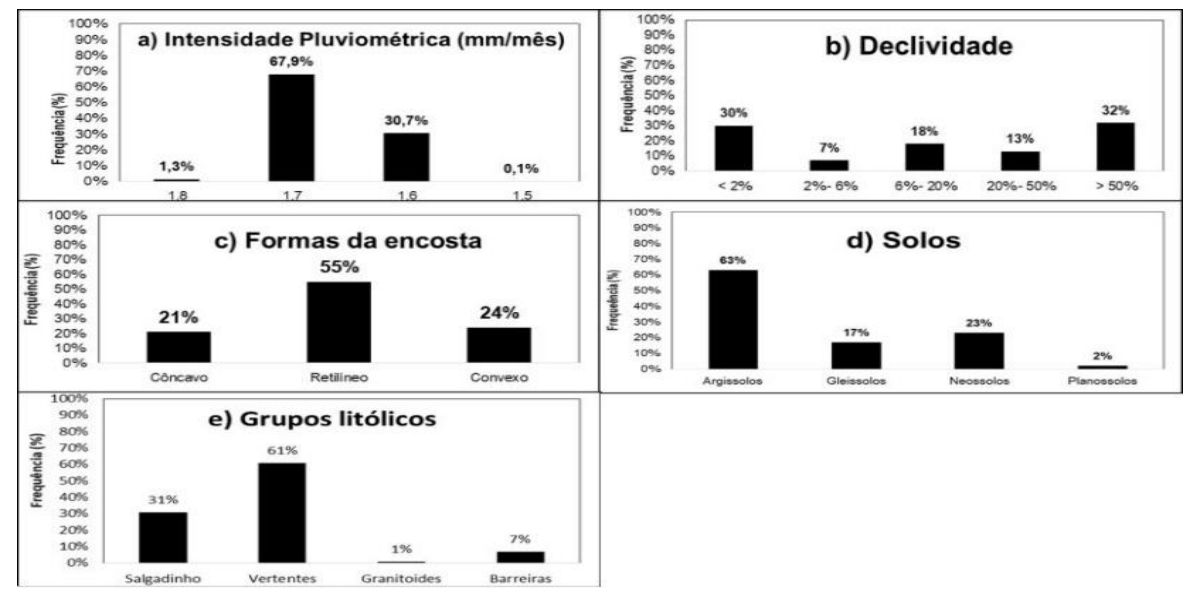

No fator declividade (Figura 3), a classe de suscetibilidade com grau fraco $(<2 \%)$ apresentou uma FD de $30 \%$ (Figura 4). As classes com graus de suscetibilidade média-fraca ( $2 \%$ e $6 \%$ ); fraca (6\% e $20 \%$ ) e média-forte (20\% e $50 \%$ ) apresentaram uma FD de $7 \%, 18 \%$ e $13 \%$, respectivamente (Figura 4). A classe de declividade $>50 \%$ (maior grau), apresentou uma FD de 32\% (Figura 4).

Quanto às curvaturas (Figura 3), a forma convexa (mais estável) possui uma FD de 24\%; a forma retilínea, com grau 2, uma FD de $55 \%$ e a forma côncava (suscetibilidade forte) uma FD de 21\% (Figura 4). Em comparação com o fator declividade, as encostas declivosas coincidem, em sua maioria, com as formas convexas, ou seja, as encostas íngremes (onde o runoff apresenta mais energia e maior capacidade de erosão), localizam-se em formas convexas, que ajudam na dissipação da energia deste runoff. Por último, o fator litologia (Figura 3) apresentou a presença de um grau médio de suscetibilidade, uma vez que os litotipos dos Complexos Vertente e Salgadinho apresentaram uma FD de 92\% e estão distribuídos em praticamente todo o 
município (Figura 4). Os Granitoides indiscriminados, mais resistentes a erosão, estão presentes em apenas 1\% da área e concentrados a oeste (Figura 3 e Figura 4). Os arenitos (Formação Barreiras), considerados os mais suscetíveis, perfazem apenas 7\%, localizados a oeste e a sul (Figura 3 e Figura 4).

Existe uma forte tendência de um ambiente denominado intergrade, onde há um balanço entre a morfogênese e a formação de solos. Isso porque na maioria dos fatores há uma presença elevada de classes que receberam um grau de suscetibilidade a erosão médio. Esta situação se reflete na carta de suscetibilidade (Figura 5), uma vez que a suscetibilidade média possui uma FD de 69,8\% (Figura 6). A classe média-forte, nesta carta, apresentou uma FD de $29,8 \%$ restrita a áreas com interação entre argissolos, arenitos (Formação Barreiras) e altas declividades, a oeste e a sul. A suscetibilidade média-fraca $(0,2 \%)$ coincidiu em áreas de declividade baixa, menor intensidade pluviométrica e presença de planossolos a sudoeste (Figura 5).

Figura 5. Carta de Suscetibilidade a erosão do município de Aliança - PE na qual se observa também a distribuição das cicatrizes erosivas mapeadas, além da frequência de distribuição (FD) das classes de suscetibilidade. Fonte: autores.

\section{CARTA DE SUSCETIBILIDADE A EROSÃO}
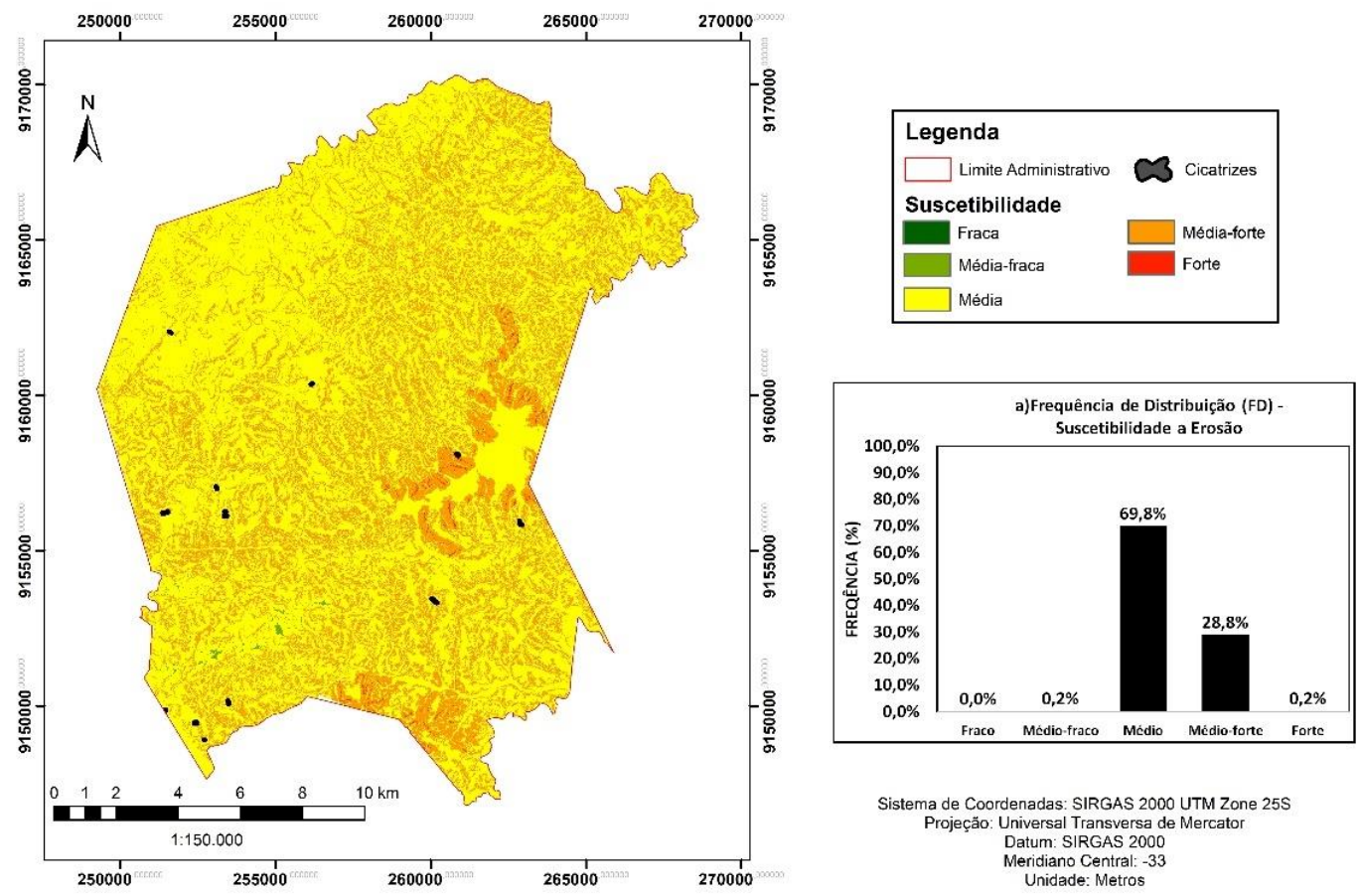

\section{Carta de Uso e Ocupação da terra}

O município possui como principal uso a monocultura de cana-de-açúcar que, embora já tenha decrescido ao longo dos anos, ainda apresenta uma FD de 52\% (Figura 6). As terras não cultivadas foram substituídas por vegetação herbácea, consideradas de transição, na medida em que ainda não possuem um manejo definido. Assim, tais áreas são utilizadas como pastagem natural ou para o uso de outros tipos de plantio tanto de ciclo curtos (ex. milho) quanto para o plantio do eucalipto, cuja FD foi de $18 \%$ (Figura 6). 
A classe pastagem (pecuária bovina extensiva) intensifica a erosão em função do pisoteio do gado e possui uma FD de 18\% (Figura 6). O uso para o plantio de espécies destinados às áreas agrícolas ocorrem em $8 \%$ no município e ainda que essa presença seja relativamente pequena em comparação com os outros tipos de uso, ainda assim é bastante relevante para a economia local (Figura 6). A área edificada possui um grau de erosão médio-fraco devido a impermeabilização do solo e a redução do escoamento superficial com FD de apenas 2\% (Figura 6). 0 solo exposto, situação mais instável, ocorre em apenas 0,5\% da área (Figura 6) e os demais usos (áreas de matas e açudes) possuem os menores graus de importância devido à inexistência de processos erosivos nessas áreas.

Figura 6. Carta de uso e ocupação da terra (2016) do município de Aliança - PE (a), Graus de importância a erosão com base nos tipos de uso (b) e Frequência de Distribuição (FD) das classes de uso da terra (c). Fonte: autores.

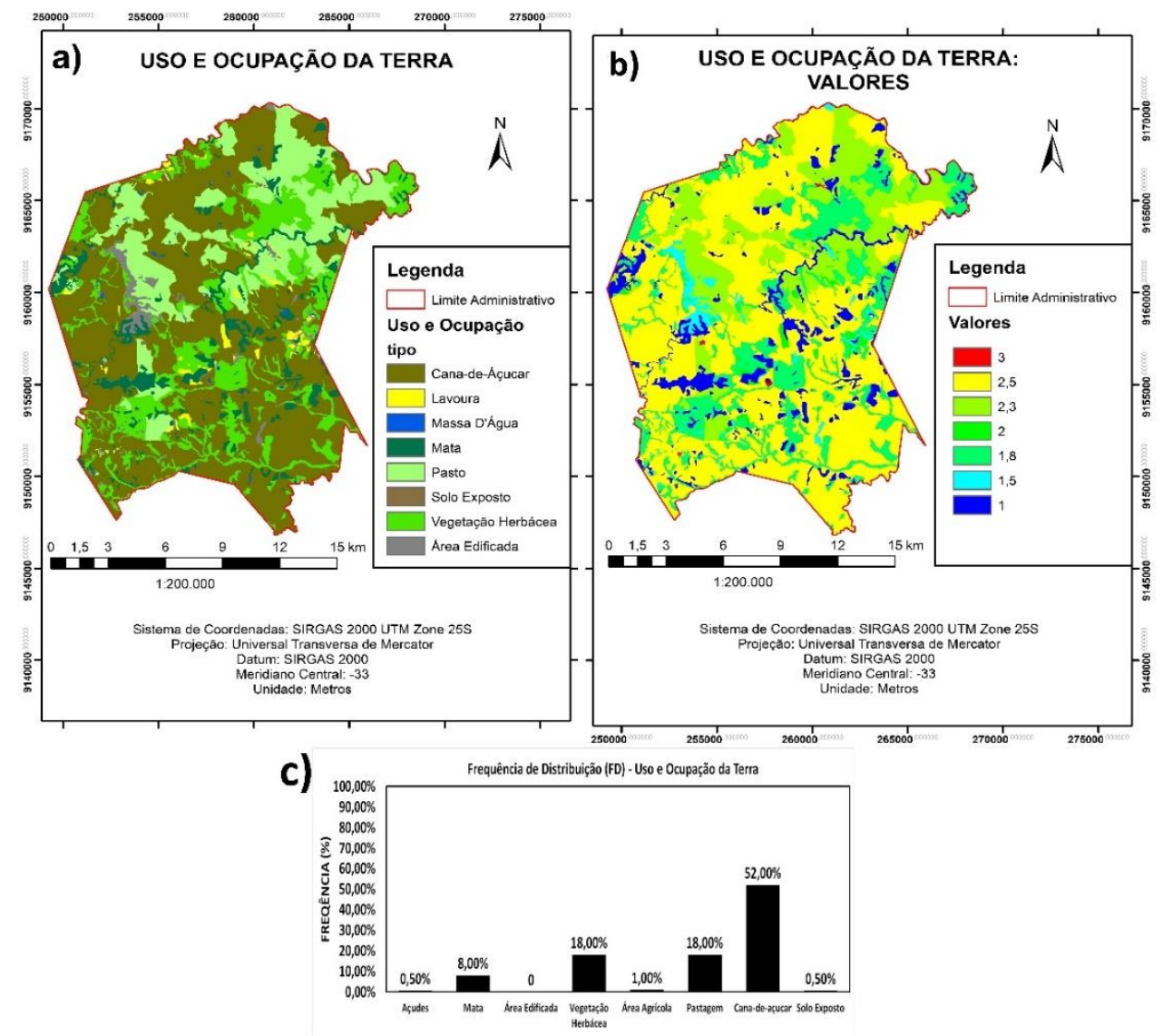

\section{Carta de Perigo a Erosão e Validação}

A carta de perigo apresentou uma FD de 65\% de grau médio-forte (Figura 7), devido à presença elevada de usos para o cultivo da cana-de-açúcar, com grande influência na gênese dos processos erosivos. A segunda classe de perigo com maior frequência é o médio, com uma FD de $28,3 \%$ e que se localiza, principalmente, nas áreas de vegetação herbácea (Figura 7). A classe de perigo médio-fraco apresentou uma FD de 6,5\% e foi 
estabelecida, sobretudo, em função de áreas de mata. Nas classes de perigo fraco e forte, as erosões praticamente não apareceram, tendo ambas uma frequência de 0,1\% (Figura 7).

A carta de perigo sofreu maior influência do uso da terra (condicionantes antrópicos) em relação à suscetibilidade natural, indicando que, mesmo em áreas pouco suscetíveis, os tipos de uso e o seu manejo inadequado provocaram a existência de processos erosivos, evidenciando que a paisagem é bastante sensível e dinâmica as modificações antrópicas (construção social do perigo).

Para a validação destes resultados foram mapeadas 16 cicatrizes erosivas (figura 7), classificados como ravinas em função de sua geometria e por não atingirem o nível d'água/lençol freático. As cicatrizes se distribuem em todo o município, porém, observa-se uma concentração superior a oeste e a sudoeste. Assim, 90,6\% das feições erosivas apresentaram uma Concentração de Erosão (CE) na classe de perigo médio-forte, indicando que houve sucesso na modelagem aplicada na previsão do perigo e na localização das cicatrizes, confirmando, portanto, a eficiência dos mapeamentos (Figura 7).

Figura 7. Carta de perigo a erosão do município de Aliança - PE com a distribuição das cicatrizes erosivas mapeadas. a) Frequência de Distribuição (FD) e b) Índice Concentração de Erosão (CE) Fonte: autores.

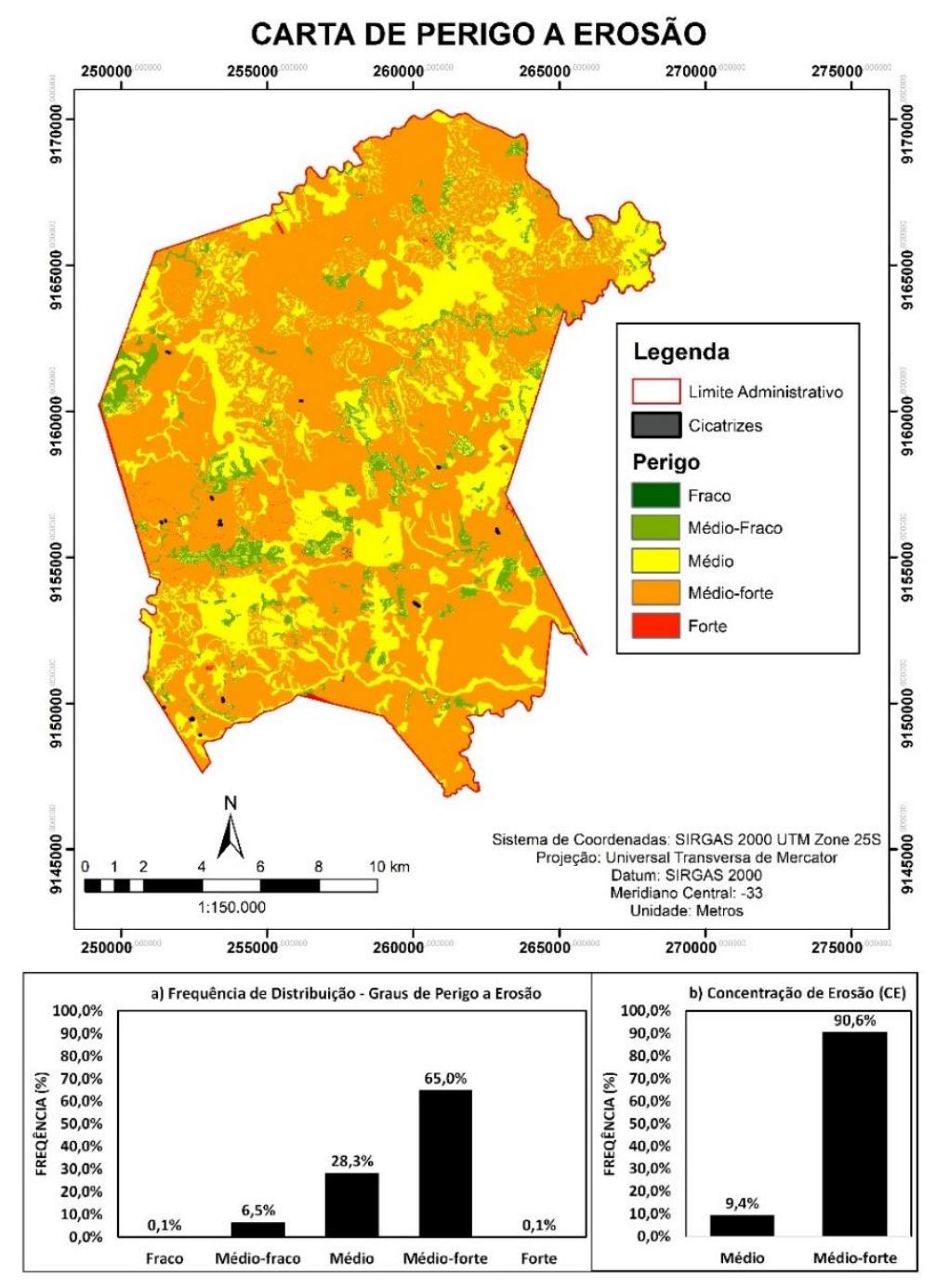


Messias e Ferreira (2017), utilizaram a logica fuzzy para mapear a "fragilidade" a erosão do Parque Nacional da Serra da Canastra no contexto do cerrado mineiro, utilizando as variáveis de Índice de Vegetação, Declividade, Densidade de Lineamento e Densidade de Vias de Circulação. Os pesos utilizados na pesquisa foram definidos a partir da correlação positiva das variáveis e o mapa de ocorrência de 1.257 cicatrizes de ravinas. Houve maior correlação nas variáveis de Densidade de Lineamento, Índice de Vegetação e Declividade, que acabaram recebendo os maiores pesos. Embora se tenha o mapa de ocorrências o autor não o utilizou para validar o resultado final.

Valladares, et al. (2012) aplicaram a metodologia multicritério na área rural no centro-oeste do Estado de São Paulo, aplicando peso de 50\% para o tema pedologia, de $30 \%$ para uso e cobertura das terras e de $20 \%$ para o fator do relevo. O resultado foi comparado com a Equação Universal de Perda de Solos e presentou bastante semelhança na distribuição espacial da suscetibilidade a erosão. Fantinel e Benedetti (2016), no município de Piratini no Rio Grande do Sul utilizaram as variáveis de pedologia (peso 30\%), declividade (Peso 30\%), litologia (Peso 20\%) e uso do solo (Peso 20\%) o resultado mostra que $72,07 \%$ da área de estudo apresenta alto perigo a erosão. Estes trabalhos não apresentaram validação por mapa de inventário ou ocorrências de erosão.

Em Pernambuco, O trabalho de Menezes et al. (2007) em uma bacia no semiárido, também se baseou em Crepani et al. (1996) para definir os pesos das variáveis (Litologia, Geomorfologia, Pedologia, Clima, Índice de Vegetação e Uso da terra), como resultado a bacia apresentou de forma geral perigo médio a erosão. Silva e Barbosa Neto (2016) aplicou a mesma metodologia de Menezes et al. (2007) na bacia do rio Beberibe, na Região Metropolitana do Recife (área de estudo mais próxima a mata norte de Pernambuco) acrescentando a variável de Índice Pluviométrico. Da mesma forma, os resultados apontaram para uma suscetibilidade mediana na área de estudo. Ambos os trabalhos não utilizaram média ponderada na integração das variáveis e não apresentaram qualquer tipo de validação destes resultados.

Das cicatrizes mapeadas, cinco foram utilizadas para uma validação mais detalhada e receberam uma nomenclatura específica ( 1 a C5) visando facilitar esta análise. Quanto à intensidade pluviométrica, as cinco cicatrizes coincidiram com a classe média-fraca, evidenciando que a pluviometria tem, possivelmente, um papel menor na deflagração dos processos erosivos para Aliança (Tabela 7). Pedologicamente, as cicatrizes C1 e C2 ocorrem sobre Argissolos, estando as demais sobre Neossolos, ambos classificados com forte suscetibilidade erosiva (Tabela 7). No fator declividade, apenas a C5 possui uma declividade íngreme (>50\%) e as demais possuem uma declividade de $20 \%-50 \%$ (média-forte) (Tabela 7 ).

Quanto as formas da encosta, as cicatrizes C1 e C2 localizam-se em relevos côncavos (grau forte). A C3 coincidiu entre as formas côncavas e retilíneas (classificadas com grau forte e média respectivamente). Já as cicatrizes $\mathrm{C} 4$ e $\mathrm{C} 5$ estão em áreas convexas e retilíneas, classificadas com grau fraco e médio, respectivamente. 
Com relação à litologia, apenas a C5 está no contexto do Complexo Salgadinho, estando as demais no contexto do Complexo Vertentes (Tabela 7). Ambos os litotipos foram classificados como suscetibilidade média e possuem a maior FD no município.

Tabela 7. Tabela comparativa das 5 cicatrizes com os fatores condicionantes naturais. Fonte: autores.

\begin{tabular}{|c|c|c|c|c|c|}
\hline Cicatrizes & $\begin{array}{c}\text { Intensidade } \\
\text { Pluviométrica }\end{array}$ & Solos & Declividade & $\begin{array}{l}\text { Forma do } \\
\text { relevo }\end{array}$ & Litologia \\
\hline C1 e C2 & $\begin{array}{c}1,7 \\
\text { (média-fraca) }\end{array}$ & $\begin{array}{l}\text { Argissolo Vermelho- } \\
\text { amarelo }\end{array}$ & $20-50 \%$ & Côncavo & $\begin{array}{l}\text { Complexo } \\
\text { Vertentes }\end{array}$ \\
\hline C3 & $\begin{array}{c}1,7 \\
\text { (média-fraca) }\end{array}$ & Neossolo Litólico & $20-50 \%$ & $\begin{array}{l}\text { Côncavo e } \\
\text { Retilíneo }\end{array}$ & $\begin{array}{l}\text { Complexo } \\
\text { Vertentes }\end{array}$ \\
\hline C4 & $\begin{array}{c}1,7 \\
\text { (média-fraca) }\end{array}$ & Neossolo Litólico & $20-50 \%$ & $\begin{array}{l}\text { Convexo e } \\
\text { Retilíneo }\end{array}$ & $\begin{array}{l}\text { Complexo } \\
\text { Vertentes }\end{array}$ \\
\hline C5 & $\begin{array}{c}1,6 \\
\text { (média-fraca) }\end{array}$ & Neossolo Litólico & $>50 \%$ & $\begin{array}{l}\text { Convexo e } \\
\text { Retilíneo }\end{array}$ & $\begin{array}{l}\text { Complexo } \\
\text { Salgadinho }\end{array}$ \\
\hline
\end{tabular}

Por fim, apresenta-se, de forma comparativa, as cinco cicatrizes avaliadas em detalhe em relação aos mapas de suscetibilidade, de uso e ocupação da terra e de perigo a erosão (Figura 8). Observa-se, portanto, que as cinco cicatrizes se localizaram em classes de suscetibilidade média-forte e média; usos de cana-deaçúcar e em classes com grau de perigo médio-forte (Figura 8).

Figura 8. Análise detalhada das 5 cicatrizes com as Cartas de Suscetibilidade; Uso e Ocupação e Perigo. Fonte: autores.

\begin{tabular}{|c|c|c|c|c|c|}
\hline & Fото & $\begin{array}{l}\text { SUSCETIBILIDADE } \\
\text { A EROSÁAO }\end{array}$ & $\begin{array}{l}\text { USO E OCUPACĀ̄o } \\
\text { DA TERRA }\end{array}$ & $\begin{array}{l}\text { PERIGOA A } \\
\text { EROSÁO }\end{array}$ & DADOS \\
\hline $\begin{array}{l}\mathrm{C} 1 \\
\mathrm{e} \\
\mathrm{c} 2\end{array}$ & & & & & 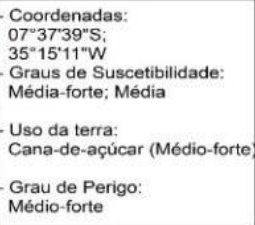 \\
\hline C3 & & 4 & & & 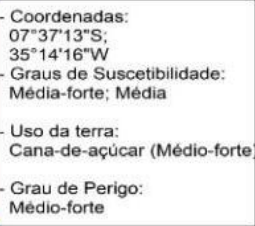 \\
\hline C4 & 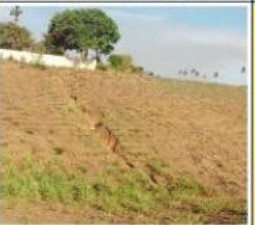 & & & & 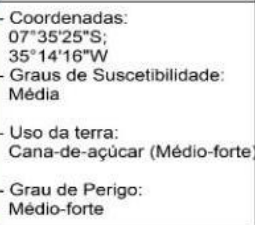 \\
\hline C5 & $\frac{100}{25}$ & E & & & 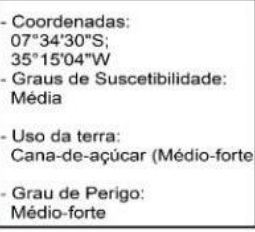 \\
\hline
\end{tabular}




\section{CONSIDERAÇÕES FINAIS}

Embora possa existir um grau de subjetividade em análises multicritérios, esta pesquisa teve o cuidado de utilizar os valores mais consagrados pela literatura geomorfológica em cada um dos fatores condicionantes avaliados, além de validações de campo. Dessa forma, os resultados das cartas de suscetibilidade e de perigo indicaram que embora haja solos altamente erodíveis no município, a capacidade da chuva erodi-los é relativamente fraca, revelando, que outros fatores condicionantes (incluindo a própria suscetibilidade pedológica) e os fatores antrópicos (especialmente o manejo) possuam um papel relevante na deflagração dos processos erosivos. Especificamente para a carta de perigo, foi possível observar um grau mais alto em relação a de suscetibilidade (grau médio-forte), confirmando que mesmo áreas de baixa suscetibilidade foram atingidas devido as intervenções antrópicas (pressões antropogênicas) na paisagem.

Para a reversão do quadro de perigo é importante a utilização de técnicas de manejo consagradas na literatura referentes à conservação dos solos, tais como práticas de caráter edáfico (controle de queimadas, rotação de cultura, calagem, entre outras) e de caráter mecânico (plantio em contorno, terraceamento, etc).

A validação comprovou a eficiência da modelagem matemática e dos dados utilizados nela, uma vez que a maioria das cicatrizes concentra-se nas classes com os maiores graus de perigo. Portanto, o município de Aliança possui um perigo médio-forte a erosão, sendo necessário um adequado planejamento urbano. Além disso, nas áreas em que predominam cultivos agrícolas, ocorreram às classes mais suscetíveis à erosão, exigindo um cuidado técnico no manejo do solo. Dessa forma, os produtos cartográficos, bem como as análises realizadas podem ser utilizados pela gestão pública no melhor planejamento do território ao integrarem ferramentas administrativas, tais como Planos Diretores e as Leis Orgânicas do município.

\section{REFERÊNCIAS}

ALMEIDA, Maria Cristina Jacinto de; FREITAS, Carlos Geraldo Luz de. Uso do Solo Urbano: suas relações com o meio físico e problemas decorrentes. In: SIMPÓSIO BRASILEIRO DE CARTOGRAFIA GEOTÉCNICA, 2., 1996, São Carlos. Anais... São Carlos: ABGE, 1996. p. 195-200.

AUGUSTO FILHO, Oswaldo. Carta de Risco de Escorregamentos Quantificada em Ambiente de SIG como Subsídio para Planos de Seguro em Áreas Urbanas: um ensaio em Caraguatatuba (SP). 2001. 195f. Tese (Doutorado em Geociências) - Instituto de Geociências e Ciências Exatas, Universidade Estadual de São Paulo, Rio Claro, 2001.

BRAGA, Tania Moreira; OLIVEIRA, Elzira Lucia de; GIVISIEZ, Gustavo Henrique Naves. Avaliação de metodologias de mensuração de risco e vulnerabilidade social a desastres naturais associados à mudança climática. São Paulo em Perspectiva, São Paulo, v.20, n.1, p.81-95. jan/mar. 2006.

BRASIL. CARVALHO, Celso Santos; MACEDO, Eduardo Soares de; OGURA, Agostinho Tadashi. Ministério das Cidades/Instituto de Pesquisas Tecnológicas - IPT (Org.). Mapeamento de Riscos em Encostas e Margem de Rios. Brasília: Ministério das Cidades; Instituto de Pesquisas Tecnológicas - IPT, 2007. 176p.

CASTRO, Cleber Marques de; PEIXOTO, Maria Naíse de Oliveira; RIO, Gisela Aquino Pires do. Riscos Ambientais e Geografia: conceituações, abordagens e escalas. Anuário do Instituto de Geociências - UFRJ, Rio de Janeiro, v.28, n.2, p. 11-30. jun. 2005. 
COMPANHIA DE PESQUISA DE RECURSOS MINERAIS. Ministério de Minas e Energia. Projeto Cadastro de Fontes de Abastecimento por Água Subterrânea Estado de Pernambuco: Diagnóstico do município de Aliança. 1. ed. Recife: CPRM/PRODEEM, 2005. 20p.

CREPANI, Edison; MEDEIROS, José Simeão de; HERNANDEZ FILHO, Pedro; FLORENZANO, Teresa Gallotti; DUARTE, Valdete; BARBOSA, Cláudio Clemente Faria. Sensoriamento remoto e geoprocessamento aplicados ao zoneamento ecológico-econômico e ao ordenamento territorial. 1. ed. São José dos Campos: INPE, 2001. 124p.

FANTINEL, Roberta Aparecida; BENEDETTI, Ana Caroline Paim. Avaliação dos Fatores Influentes na Vulnerabilidade À Erosão do Solo por Meio de Decisão Multicritério e de Técnicas de Geoprocessamento no Município De Piratini - Rs. Ciência e Natura, Santa Maria, v.38, n.1, p;156-163. jan/abr. 2016.

MARANDOLA JUNIOR, Eduardo; HOGAN, Daniel Joseph. Natural hazards: o estudo geográfico dos riscos e perigos. Ambiente \& Sociedade, Campinas, v.7, n.2, p. 95-109. jul/dez. 2004.

MEIRELLES, Margareth Simões Penello; MOREIRA, Fábio Roque; CÂMARA, Gilberto; COELHO NETO, Ana Luiza; CARNEIRO, Thales Alfredo de Avila. Métodos de Inferência Geográfica: Aplicação no planejamento regional, na avaliação ambiental e na pesquisa mineral. In: MEIRELLES, Margareth Simões Penello; CÂMARA, Gilberto; ALMEIDA, Cláudia Maria de (Org.). Geomática: Modelos e Aplicações Ambientais. 1. ed. Brasília: Embrapa Informação Tecnológica, 2007. 593p. p. 283-386.

MENEZES, Jéssica Bezerra de; ARAÚJO, Maria do Socorro Bezerra de, GALVÍNCIO, Josiclêda Domiciano; SAMPAIO, Everardo Valadares de Sá Barretto, CORRÊA, Antônio Carlos de Barros. Índice de vulnerabilidade à erosão para uma bacia na Mesorregião do São Francisco Pernambucano, a partir das relações entre morfogênese e pedogênese. Revista Brasileira de Geomorfologia, São Paulo, v.8, n.2, p. 45-56. jan. 2007.

MESSIAS, Cassiano Gustavo; FERREIRA, Marcos César. Aplicação do Método de Classificação Contínua Fuzzy para o Mapeamento da Fragilidade do Terreno em Relação à Ocorrência de Ravinas no Parque Nacional da Serra da Canastra. Raega - O Espaço Geográfico em Análise, Curitiba, v.39, n.1, p. 111-127. abr. 2017.

REBELO, Fernando. Riscos Naturais e Acção Antrópica: Estudos e reflexões. 1. ed. Coimbra: Imprensa da Universidade de Coimbra, 2001. 286p.

ROSS, Jurandyr Luciano Sanches. Análise Empírica da Fragilidade dos Ambientes Naturais e Antropizados. Revista do Departamento de Geografia - USP, São Paulo, v.8, n.1, p. 63-74. nov. 1994.

SILVA, José Fábio Gomes da.; BARBOSA NETO, Manuella Vieira Análise da Vulnerabilidade a Processos Erosivos da Bacia Hidrográfica do Rio Beberibe. In: LISTO, Fabrizio de Luiz Rosito; MÜTZENBERG, Demétrio; TAVARES, Bruno de Azevedo Cavalcanti (Org.). E-book do I Workshop de Geomorfologia e Geoarqueologia do Nordeste. 1. ed. Recife: GEQUA, 2016. 268p. p. 79-88.

UNDP BUREAU FOR CRISIS PREVENTION AND RECOVERY. Reducing Disaster Risk: A challenge for development, a global report. 1. ed. New York: UNDP. 2004. 161p.

UNIVERSIDADE FEDERAL DE SANTA CATARINA. CENTRO UNIVERSITÁRIO DE ESTUDOS E PESQUISAS SOBRE DESASTRES. Atlas brasileiro de desastres naturais: 1991 a 2012 / Centro Universitário de Estudos e Pesquisas sobre Desastres. 2. ed. Florianópolis: CEPED UFSC, 2013. 130p.

VALLADARES, Gustavo Souza; GOMES, Andréa da Silva; TORRESAN, Fabio Enrique; RODRIGUES, Cristina Aparecida Gonçalves; GREGO, Célia Regina. Modelo Multicritério Aditivo na Geração de Mapas de Suscetibilidade à Erosão em Área Rural. Pesquisa Agropecuária Brasileira, Brasília, v.47, n.9, p. 1376-1383. set. 2012.

VARNES, David J. Landslide hazard zonation: A review of principles and practice. 1. ed. Paris: UNESCO, 1984. 63p.

VASCONCELOS SOBRINHO, João de. As Regiões Naturais de Pernambuco, o Meio Ambiente e Civilização. Rio de Janeiro: Freitas Bastos, 1949. 220p. 